\title{
Tendências nos estudos de Representação Temática da Informação: uma revisão integrativa dos artigos científicos indexados na Brapci
}

\author{
Camila Regina de Oliveira Rabelo \\ Mestra; Universidade Federal do Ceará, Fortaleza, CE, Brasil \\ camilareginarabelo@gmail.com \\ Virgínia Bentes Pinto \\ Doutora; Universidade Federal do Ceará, Fortaleza, CE, Brasil \\ vbentes@ufc.br
}

\begin{abstract}
Resumo: Esta pesquisa apresenta os resultados da investigação cujo objetivo básico é verificar, por meio da Revisão Bibliográfica Integrativa, as tendências dos assuntos relativos aos estudos e às pesquisas que contemplam a representação temática nos artigos científicos indexados na Base de Dados Referenciais de Artigos de Periódicos em Ciência da Informação. Entendemos a representação temática ou indexação como um esquema complexo de ações que visa identificar os assuntos principais de um documento objetivando oferecer "pistas" para a recuperação de informação. É uma pesquisa pautada na RBI, metodologia que permite sintetizar os conteúdos encontrados na literatura científica para evidenciar a manifestação de um determinado assunto e auxiliar em pesquisas posteriores. O lócus do estudo empírico foi a base de dados, tendo como recorte o período de 2012 a 2017. Os resultados evidenciam um total de 25 artigos concernentes à Representação Temática da Informação, sendo que as tendências das pesquisas contemplam: Arquivologia, indexação de documentos jurídicos, linguagens documentárias, estudos semânticos, mapas conceituais, indexação de imagens, bibliotecas universitárias, bibliotecas digitais/repositórios digitais, indexação de textos de literatura e ensino da representação temática a distância. Concluímos que as tendências dos estudos e das pesquisas sobre a Representação Temática da Informação contemplam uma diversidade de aplicações, tendo como função maior o acesso aos documentos e sua recuperação.
\end{abstract}

Palavras-chave: Revisão integrativa. Representação Temática da Informação. Indexação de assuntos. Representação da informação. Pesquisa em Ciência da Informação. 


\section{Introdução}

Originária da filosofia, a Representação Temática da Informação ou indexação está presente na pragmática da Biblioteconomia desde os seus primórdios. Entretanto, se pensarmos em "indexes", ou índices, eles apareceram com a tecnologia analógica da construção de indexes proposta pelos escribas e ficaram conhecidos pelo nome de "listas". Tais listas eram constituídas por um conjunto de palavras cujo objetivo era classificar os objetos e elaborar inventários (BOTTÉRO, 1987, p. 68). Seu destaque maior deu-se no final da Idade Média e seu avanço foi intensificado com a invenção da imprensa e com o aparecimento de bibliografias, catálogos, cabeçalhos de assuntos, sistemas de classificação bibliográfica e tesauros. Contudo, tal conceito somente aparece registrado nas publicações referentes a essa área de conhecimento por volta da década de 1940, com as novidades da informática.

A representação temática/indexação de assuntos tem como objetivo extrair ou associar os assuntos que melhor representam os conteúdos ou as temáticas registradas nos documentos, de modo a identificá-los de forma particular em meio a outros documentos independentemente, se textos verbais ou não verbais e de suportes de registros, analógicos ou digitais. Ela se efetiva por meio de palavras-chave, conceitos, descritores, termos, resumos, entre outros. No caso de textos não verbais, ela também se concretiza mediante atributos não verbais, a exemplo da textura, forma, cor ou outro signo não linguístico.

No entendimento de Bentes Pinto, Meunier e Silva Neto (2008), embora pareça uma taxa simples, em realidade configura-se como um esquema complexo de ações a serem seguidas visando indicar os conteúdos enunciados nos documentos, “[...] isso, porque, nesse esquema, estão em cena ao menos três atores: o autor do documento, o sujeito que constrói as representações indexais e os consumidores [...]" Que vêm em busca das informações para solucionar uma "anomalia de conhecimento" ou construir novos conhecimentos. Tais aspectos evidenciam a complexidade que é pensar a questão da representação da informação, fato que nos motivou a pesquisar esse tema pautando-nos no 
seguinte questionamento: que assuntos relativos aos estudos e às pesquisas concernentes à representação temática estão sendo investigados nos artigos científicos indexados na Base de Dados Referenciais de Artigos de Periódicos em Ciência da Informação (Brapci)?

A publicação de artigos científicos tem se configurado como principal canal de comunicação e divulgação da ciência e, por meio disso, novos estudos são desenvolvidos dando continuidade às pesquisas ou ainda contribuindo para o surgimento de novos trabalhos. A Brapci é um dos principais canais de divulgação científica na área de Ciência da Informação (CI), sendo considerada uma fonte importante para essa área e também para a Biblioteconomia, Arquivologia e Museologia.

Tomando por base esse questionamento e as reflexões de cunho mais geral, buscamos, como objetivo geral, verificar, por meio da Revisão Bibliográfica Integrativa (RBI), as tendências dos temas abordados nos estudos e nas pesquisas sobre a representação temática, indexados na Brapci. Com assente nesse objetivo, apontamos como objetivos específicos:

a) mapear os artigos científicos indexados na Brapci que contemplam os estudos em Representação Temática da Informação ou indexação;

b) definir as estratégias de busca para a coleta de dados conforme a sistemática da RBI;

c) analisar as categorias de assuntos que estão sendo estudados nos artigos indexados na referida base de dados, seguindo as estratégias de busca predefinidas.

Esses são os aspectos que serão tratados nesta pesquisa, norteada pela postura metodológica da RBI que, conforme Torraco (2005), enquanto procedimento de pesquisa, revisa criticamente e sintetiza a literatura representativa de um tema de investigação de forma integrada. 


\section{Algumas considerações sobre representação temática da informação}

O sentido do conceito representação nos leva a compreender que ela se efetiva a partir da preexistência de algo para que possa dar existência ou espelhar outro com as características daquilo que ela se diz representar. Por isso, a representação é um esquema complexo de ações sígnicas cognitivas ou "maquinitivas". O signo, conforme Boulnois (1999, p. 9), significa:

Stare pro (estar no lugar de) [...] dentro de uma proposição, os termos estão no lugar das coisas a que eles se referem; similitudo, species, imago (ser uma semelhança, uma imagem) o conhecimento abstrato está no lugar do objeto. (Grifo do autor).

Essa compreensão acerca da representação se faz necessária, não obstante a área de conhecimento, e, no contexto da Ciência da Informação e da Biblioteconomia, o senso da representação também precisa vir ao encontro desse entendimento, a fim de que ela não seja compreendida em uma perspectiva linear e simplista.

No campo da Ciência da Informação, enquanto área interdisciplinar desde sua gênese, a representação temática dialoga com conhecimentos advindos da Biblioteconomia, da Filosofia, da Documentação, da Computação e de outras áreas. Esses diálogos contribuem para inovar as técnicas desenvolvidas para análise de um documento, identificando os temas nele tratados e propondo alternativas que possam refletir tais temas. Por exemplo, com a Ciência da Computação, a CI dialoga, entre outros aspectos, apropriando-se dos softwares tanto para aplicar aos processos de representação/indexação automática e semiautomática, como para facilitar e acelerar a recuperação da informação. Como podemos observar, essas interlocuções evidenciam que os "conceitos de representação temática e recuperação da informação nasceram interligados, haja vista que a existência de um, necessariamente, demanda a presença do outro." (FRANÇA, 2016, p. 43). Consequentemente, a pragmática e as pesquisas dedicadas à representação temática e à recuperação da informação apresentam 
pontos comuns tanto no que se refere à possibilidade de organização da informação, como ao acesso, à mediação e à preservação da memória.

Para além da área da Computação, Campos (1995) reflete que os profissionais de distintos campos de saberes reuniram esforços para a construção de conhecimentos na área de recuperação da informação, principalmente pautados nas necessidades do pós-guerra (Segunda Guerra Mundial). A autora diz ainda que essas características contribuem também para que as pesquisas em representação ganhem forma em outras áreas, "como mostra a literatura recente", extrapolando "o domínio da documentação, o que não significa que ela abandone suas próprias teorias relacionadas com a representação, pois elas são parte integrante deste novo movimento, que tem em comum a organização do conhecimento." (CAMPOS, 1995, p. 4). Ratificando essas ideias, Lancaster (2004, p. 7) afirma que, embora em seus primórdios a indexação e a redação de resumos fossem temas de interesse somente das "bibliotecas e de algumas editoras, sua relevância e utilidade são reconhecidas hoje em dia de modo muito mais amplo, pois, obviamente, encontram aplicações em todos os tipos de recursos de informação em formato digital".

A representação temática é a base para a organização da informação e do conhecimento, mesmo quando não está sendo estudada dentro das áreas da Ciência da Informação, Biblioteconomia, Documentação, Arquivologia e Museologia. Consideramos que ela se pauta, principalmente, em cinco vias, a saber:

a) busca estratégias para a construção dos chamados instrumentos de indexação, como é o caso dos vocabulários controlados, sistemas de classificação, tesauros, ontologias, entre outros;

b) volta-se para as ações de indicação dos indícios que possam apontar para a recuperação do documento que contém a informação buscada;

c) possibilita instrumentos para a preservação das memórias históricas e socioculturais dos vários saberes;

d) contribui para a estruturação de metadados de preservação digital visando à recuperação da informação a longo termo; 
e) surge como instrumento de base para as pesquisas e os estudos sobre Arquitetura da Informação e mineração de dados, sendo aplicado a qualquer área do conhecimento, o que possibilita estudos interdisciplinares e contribuições ricas para outros campos.

Com a chegada das Tecnologias Digitais da Informação e da Comunicação (TDIC), as possibilidades de se construir a representação temática não são mais as mesmas de quando se planejava a elaboração de índices. $\mathrm{Na}$ realidade, as TDIC oferecem inovações que vão das mais simples listas de assuntos aos sofisticados estudos de inteligência artificial. Mesmo com todos os aparatos tecnológicos existentes, a Representação Temática da Informação necessita apoiar seus estudos em sua gênese e elaborar e reelaborar seus conceitos primeiros em relação ao entendimento de documentos e às necessidades de busca de seus usuários. Por mais que pareça uma área técnica, há também a preocupação com o usuário da informação, afinal é para solucionar uma "anomalia do conhecimento" que a representação é pensada. Indo ao nosso encontro, Carneiro (1985, p. 222) afirma que "o principal propósito de um serviço de indexação é assegurar da forma mais eficiente e econômica possível que qualquer documento ou informação seja fornecido ao usuário no momento preciso". Complementando essa ideia, Chaumier (1988, p. 74) enuncia que "A indexação é uma operação essencial para que se possa recuperar documentos do acervo documentário e então responder, de forma adequada e eficaz, a todo pedido ou questão dos usuários [...]”, contribuindo para minimizar os "RUÍDOS" (excesso de respostas ao que se buscou) ou os "SILÊNCIOS" (não obtenção de respostas nas buscas que foram feitas ou, ainda, não acesso a um documento existente, pois ele encontra-se perdido) (CHAUMIER, 1988, p. 47).

Para Fujita et al. (2009, p. 97), a indexação é “[...] uma operação de representação documentária cuja finalidade é direcionada a identificar e selecionar conceitos que transmitam a essência de um documento a fim de representá-lo por termos de uma linguagem documentária". Corroborando com a autora, Vieira (1988, p. 43) aponta que a indexação "condensa a informação significativa de um documento" e, portanto, funciona como "uma linguagem intermediária entre o usuário e o documento". Essa linguagem intermediária tem 
como base os assuntos que se relacionam com o documento, e a escolha das palavras adequadas será fundamental para a recuperação eficaz dos conteúdos. Seguindo a mesma linha de pensamento, Robredo (2005, p. 165) complementa afirmando que "a indexação consiste em indicar o conteúdo temático de uma unidade de informação, mediante a atribuição de um ou mais termos (ou códigos) ao documento, de forma a caracterizá-lo de forma unívoca". Essa característica fará com que o documento mantenha seu significado mesmo em meio à grande quantidade de registros existentes na mesma base de dados.

\section{Revisão bibliográfica integrativa}

Pode-se considerar a Revisão Bibliográfica Integrativa (RBI) como uma inovação da revisão bibliográfica. Trata-se de uma metodologia que tem como objetivo mapear os conteúdos dos documentos para estudar a incidência de um fenômeno por meio da constatação de sua ocorrência em outros estudos. Tal prática surge na área da Saúde por volta de 1980, no contexto da Prática Baseada em Evidências (PBE), com a proposta de relacionar os estudos científicos e profissionais. Essa junção possibilita a construção de um esquema de conhecimento que venha a auxiliar na tomada de decisão e também a contribuir para o desenvolvimento de novos estudos baseando-se nas temáticas presentes nas publicações científicas. Mendes, Silveira e Galvão (2008, p. 759) afirmam que

A revisão integrativa inclui a análise de pesquisas relevantes que dão suporte para a tomada de decisão e a melhoria da prática clínica, possibilitando a síntese do estado do conhecimento de um determinado assunto, além de apontar lacunas do conhecimento que precisam ser preenchidas com a realização de novos estudos.

Silveira e Galvão (2005, p. 227) afirmam que a RBI "tem como finalidade reunir e sintetizar o conhecimento científico já produzido sobre o tema investigado, ou seja, permite buscar, avaliar e sintetizar as evidências disponíveis para a sua incorporação na prática". O ponto forte da revisão 
integrativa é a busca de soluções para problemas que acontecem no âmbito profissional no meio científico, em que são postuladas teorias e divididos relatos de experiência. Isso porque a comunicação científica tem a função de servir de apoio tanto para a prática profissional como para a elaboração de novos estudos. Na percepção de Mendes, Silveira e Galvão (2008, p. 760), “a revisão integrativa da literatura consiste na construção de uma análise ampla da literatura, contribuindo para discussões sobre métodos e resultados de pesquisas, assim como reflexões sobre a realização de futuros estudos”.

Em comparação com os outros métodos que também propõem a revisão bibliográfica ou da literatura, a revisão integrativa apresenta uma abordagem ampla por permitir a compilação simultânea de pesquisa experimental e quase experimental, proporcionando compreensão global do tema estudado e sendo, portanto, essa uma vantagem, além de permitir a combinação entre dados teóricos e empíricos (MENDES; SILVEIRA; GALVÃO, 2008).

Apesar de ter seu surgimento no campo da Saúde, devido as suas características e a seus objetivos, acreditamos que a RBI pode ser aplicada também em outros campos do saber, afinal

Este método de pesquisa permite a síntese de múltiplos estudos publicados e possibilita conclusões gerais a respeito de uma particular área de estudo. [...] o revisor pode elaborar uma revisão integrativa com diferentes finalidades, ou seja, ela pode ser direcionada para a definição de conceitos, a revisão de teorias ou a análise metodológica dos estudos incluídos de um tópico particular. (MENDES; SILVEIRA; GALVÃO, 2008, p. 759).

De acordo com esse entendimento, utilizamos esse tipo de pesquisa para a realização do estudo em lide, seguindo as fases propostas por Ganong (1987) e Souza, Silva e Carvalho (2010), descritas como: elaboração da pergunta norteadora, busca ou amostragem na literatura, coleta de dados, análise crítica dos estudos incluídos, discussão dos resultados e apresentação da revisão integrativa.

Na primeira fase da RBI, é definida a questão norteadora da pesquisa que será a âncora do trabalho. Souza, Silva e Carvalho (2010, p. 10) dizem que é a 
"fase mais importante da revisão, pois determina quais serão os estudos incluídos, os meios adotados para a identificação e as informações coletadas de cada estudo selecionado". Após a elaboração do questionamento, a segunda fase concerne à busca ou à amostragem na literatura; assim, "os critérios de amostragem precisam garantir a representatividade da amostra, sendo importantes indicadores da confiabilidade e da fidedignidade dos resultados." (SOUZA; SILVA; CARVALHO, 2010, p. 104).

Para garantir a coleta e assegurar que todos os dados relevantes sejam extraídos, na terceira fase da RBI faz-se necessária a utilização de instrumentos elaborados anteriormente, os quais objetivam diminuir os riscos na transição das informações, servindo, dessa forma, como garantia. Os instrumentos de coleta devem ser definidos de acordo com o objetivo da pesquisa e com o objeto do estudo e poderão facilitar a análise crítica dos dados, que é a quarta fase da RBI. A análise crítica dos estudos incluídos correspondente à análise dos dados nas pesquisas convencionais requer uma abordagem organizada que considere as características próprias de cada estudo (SOUZA; SILVA; CARVALHO, 2010).

A discussão dos resultados é o diálogo entre o pesquisador e os resultados encontrados, no qual serão colocados à prova suas hipóteses e seus questionamentos, assim como as contribuições para o objeto que está sendo evidenciado no estudo. Por fim, os autores Souza, Silva e Carvalho (2010, p. 106) propõem a apresentação da RBI de forma "clara e completa para permitir ao leitor avaliar criticamente os resultados". Acreditamos que essas duas etapas finais são complementares, sendo a solidificação da RBI, e que podem ser apresentadas juntas para que o leitor visualize os resultados obtidos na pesquisa e as considerações do pesquisador.

\subsection{O estudo empírico}

Iniciamos o estudo empírico com a pergunta norteadora: que assuntos relativos aos estudos e às pesquisas, contemplando a representação temática, estão sendo investigados nos artigos científicos indexados na Base de Dados 
Referenciais de Artigos de Periódicos em Ciência da Informação (Brapci)? Esse questionamento se refere a mapear as aplicações dos estudos em Representação Temática da Informação e identificar as categorias de assuntos que estão sendo estudadas nesse campo, pois sabemos que se trata de uma temática de pesquisa da CI que apresenta contribuições interdisciplinares. Para isso, definimos que seriam considerados documentos que tivessem como foco o estudo da representação temática ou indexação de assuntos.

A busca ou amostragem na literatura foi realizada na Brapci, utilizada como lócus para este estudo. É uma base de dados referenciais de acesso aberto, que apresenta uma vasta gama de documentos na área de CI publicados a partir do ano de 1972 e reúne um acervo de 57 revistas científicas, 18.536 trabalhos (artigos) em revistas científicas, 2.482 trabalhos publicados em eventos, 2 livros e 1 tese. A base é mantida pela Universidade Federal do Paraná e surgiu como resultado do incentivo do projeto de pesquisa "Opções metodológicas em pesquisa: a contribuição da área da informação para a produção de saberes no ensino superior", financiado pelo Conselho Nacional de Desenvolvimento Científico e Tecnológico (CNPq). Configura-se como uma fonte de informação legítima e confiável, que armazena a produção científica na área de CI e possibilita a busca de documentos por meio da estratégia: autores, título, resumo, palavras-chave, referências, ano, ou ainda pela junção ou busca avançada de todos esses campos.

No que concerne à coleta de dados, terceira fase da RBI, escolhemos os artigos que constituiriam o corpus da pesquisa. Assim, selecionamos os artigos científicos publicados em periódicos de CI nos últimos cinco anos, o que significa um recorte temporal de 2012 a 2017. O critério de seleção desses artigos foi que deveriam abordar como um dos objetos de estudo a Representação Temática da Informação ou indexação. A estratégia de busca foi o sintagma "Representação Temática da Informação". Elaboramos uma planilha para a coleta de dados contendo os metadados: autores, título, aplicação do assunto/temática, ano e periódico, para armazenamento e tratamento dos dados coletados. Para o preenchimento da planilha e mapeamento dos assuntos/temáticas dos artigos, foi necessária a leitura dos títulos, dos resumos e 
das introduções, dos títulos das seções e, em alguns casos, até mesmo dos documentos na íntegra.

Após a delimitação metodológica e a escolha dos artigos que atendem a nossa proposta de pesquisa, apresentamos a seguir a fase da análise crítica dos dados coletados. Assim, a primeira pesquisa foi feita por título, do quais obtivemos 7 resultados; no entanto, apenas 4 artigos de periódicos foram selecionados. Na busca por palavras-chave, foram recuperados 8 documentos, sendo 4 artigos de periódicos. Quando buscamos por resumo, 15 registros foram apresentados, e deles 4 artigos selecionados. Na última tentativa de busca, escolhemos a opção de utilizar todos os campos e obtivemos um total de 112 documentos. Desses, selecionamos somente os artigos publicados em periódicos científicos e retiramos aqueles que se repetiam conforme as buscas já realizadas, resultando, assim, na seleção de 14 artigos. No total, localizamos 25 que atenderam aos critérios por nós estabelecidos.

Nesses 25 artigos, também mapeamos 10 categorias de assuntos relativos à representação temática. A estratégia foi categorizar os assuntos abordados nos artigos conforme as semelhanças apresentadas nas pesquisas, quais sejam: estudos na Arquivologia, indexação de documentos jurídicos, estudo de linguagens documentárias, estudos semânticos, mapas conceituais, indexação de imagens, bibliotecas universitárias, bibliotecas digitais/repositórios digitais, indexação de textos de literatura, ensino da Representação Temática da Informação na modalidade a distância.

Tabela 1 - Tendências temáticas de aplicação da representação da informação nos artigos indexados na Brapci. 
Na apresentação e discussão dos resultados, nossa decisão foi apresentá-los na íntegra em forma de quadros para melhor visualização dos dados referentes aos artigos recuperados e às informações relacionadas a eles. $\mathrm{Na}$ primeira categoria (quadro 1), identificamos dois artigos que trazem a representação temática no campo de estudo da Arquivologia.

Quadro 1 - Estudos na Arquivologia

\begin{tabular}{|c|c|c|c|c|}
\hline \multicolumn{5}{|c|}{ Estudos na Arquivologia } \\
\hline Autores & Título do artigo & Palavras-chave & Ano & Periódico \\
\hline $\begin{array}{l}\text { SILVA, M. R. } \\
\text { B.; SOUSA, } \\
\quad \text { D. E. L.; } \\
\text { BANDEIRA, } \\
\text { P. M. }\end{array}$ & $\begin{array}{c}\text { A representação } \\
\text { temática em } \\
\text { documentos } \\
\text { arquivísticos: o caso da } \\
\text { indexação documental } \\
\text { realizada pelos alunos } \\
\text { de Arquivologia da } \\
\text { UFPB. }\end{array}$ & $\begin{array}{l}\text { Arquivo. Representação } \\
\text { Temática da } \\
\text { Informação. Indexação. } \\
\text { Norma Brasileira de } \\
\text { Descrição Arquivística. } \\
\text { Nobrade. }\end{array}$ & 2012 & $\begin{array}{l}\text { InCID: Revista } \\
\text { de Ciência da } \\
\text { Informação e } \\
\text { Documentação }\end{array}$ \\
\hline $\begin{array}{l}\text { MEDEIROS, } \\
\text { G. M.; } \\
\text { VITAL, L. P.; } \\
\text { BRÄSCHER, } \\
\text { M. }\end{array}$ & $\begin{array}{l}\text { Tratamento temático } \\
\text { da informação em } \\
\text { documentos } \\
\text { arquivísticos: estudo } \\
\text { dos anais da ISKO e } \\
\text { do GT2 do Enancib. }\end{array}$ & $\begin{array}{l}\text { Tratamento temático da } \\
\text { informação. } \\
\text { Representação de } \\
\text { assunto. Documentos } \\
\text { arquivísticos. }\end{array}$ & 2016 & $\begin{array}{l}\text { Tendências da } \\
\text { Pesquisa } \\
\text { Brasileira em } \\
\text { Ciência da } \\
\text { Informação }\end{array}$ \\
\hline
\end{tabular}

Fonte: Dados da pesquisa.

No primeiro trabalho, temos um relato de experiência dos estudantes que cursaram a disciplina Representação Temática da Informação Arquivística II, na atividade de extração dos assuntos de documentos arquivísticos correntes. Tal artigo destaca a importância da indexação que, embora tenha sua origem como uma atividade biblioteconômica, também é realizada na arquivista. Por sua vez, o segundo artigo expõe os temas apresentados nos anais de dois importantes eventos que reúnem trabalhos da CI, destacando aqueles que se relacionam com a representação temática e com os documentos arquivísticos. Essa categoria evidencia que a indexação de documentos é também um objeto de estudo da Arquivologia. Nessa categoria, Silva, Sousa e Bandeira (2012, p. 139) percebem "que a Indexação na Arquivologia deve usar como base as teorias apresentadas na Biblioteconomia, onde se encontra enraizada e muito discutida [...]", fato evidenciado nos trabalhos analisados. 
Quadro 2 - Indexação de documentos jurídicos

\begin{tabular}{|c|c|c|c|c|}
\hline \multicolumn{5}{|c|}{ Indexação de documentos jurídicos } \\
\hline Autores & Título do artigo & Palavras-chave & Ano & Periódico \\
\hline $\begin{array}{l}\text { FERREIRA, } \\
\text { A. C.; } \\
\text { MACULAN, } \\
\text { B. C. M. S. }\end{array}$ & $\begin{array}{c}\text { Organização da } \\
\text { informação jurídica: } \\
\text { proposta de modelo de } \\
\text { leitura técnica de acórdãos } \\
\text { no contexto do controle } \\
\text { externo. }\end{array}$ & $\begin{array}{l}\text { Modelo de leitura } \\
\text { técnica. Indexação. } \\
\text { Jurisprudência. } \\
\text { Informação } \\
\text { jurídica. Tribunal } \\
\text { de Contas. }\end{array}$ & 2016 & $\begin{array}{l}\text { Revista ACB: } \\
\text { Bibliotecono- } \\
\text { mia em Santa } \\
\text { Catarina }\end{array}$ \\
\hline $\begin{array}{l}\text { FERREIRA, } \\
\text { A. C.; } \\
\text { MACULAN, } \\
\text { B. C. M. S.; } \\
\text { ALMEIDA, J. } \\
\text { F. V. R. }\end{array}$ & $\begin{array}{l}\text { Fundamentos teóricos da } \\
\text { representação temática da } \\
\text { informação jurídica. }\end{array}$ & $\begin{array}{c}\text { Informação } \\
\text { jurídica. } \\
\text { Representação } \\
\text { temática. Indexação } \\
\text { - fundamentos } \\
\text { teóricos. }\end{array}$ & 2017 & $\begin{array}{l}\text { CAJUR - } \\
\text { Caderno de } \\
\text { Informações } \\
\text { Jurídicas }\end{array}$ \\
\hline
\end{tabular}

Fonte: Dados da pesquisa.

As duas propostas apresentadas no quadro 2 são muito semelhantes e abordam a indexação para documentos jurídicos como possibilidade de melhorar a recuperação da informação nesses documentos. De acordo com Ferreira, Maculan e Almeida (2017, p. 8), “A indexação, também conhecida como representação temática, objetiva proporcionar, aos operadores do Direito, o acesso ao(s) assunto(s) contido(s) na legislação, na doutrina e na jurisprudência", daí o porquê de toda atenção na concretização do esquema indexal, pois o resultado deverá agilizar o acesso da busca de informações no campo jurídico ou em qualquer outro. Com esse entendimento, pode-se evitar tanto o ruído quanto o silêncio, conforme bem argumenta Chaumier (1988).

Quadro 3 - Estudo de linguagens documentárias

\begin{tabular}{|c|c|c|c|c|}
\hline \multicolumn{5}{|c|}{ Estudo de linguagens documentárias } \\
\hline Autores & Título do artigo & Palavras-chave & Ano & Periódico \\
\hline $\begin{array}{l}\text { OLIVEIRA, } \\
\text { D. A.; } \\
\text { ARAÚJO, R. } \\
\text { F. }\end{array}$ & $\begin{array}{c}\text { Construção de } \\
\text { linguagens } \\
\text { documentárias em } \\
\text { sistemas de recuperação } \\
\text { da informação: a } \\
\text { importância da garantia } \\
\text { do usuário. }\end{array}$ & $\begin{array}{c}\text { Ciência da } \\
\text { Informação. } \\
\text { Biblioteconomia. } \\
\text { Garantia do usuário. } \\
\text { Organização do } \\
\text { conhecimento. } \\
\text { Tesauros. } \\
\text { Representações } \\
\text { documentárias. } \\
\text { Indexação. }\end{array}$ & 2012 & $\begin{array}{l}\text { Encontros } \\
\text { Bibli: Revista } \\
\text { Eletrônica de } \\
\text { Bibliotecono- } \\
\text { mia e Ciência } \\
\text { da Informação }\end{array}$ \\
\hline $\begin{array}{l}\text { SOUSA, B. P. } \\
\text { de; SILVA, F. } \\
\text { P. da }\end{array}$ & $\begin{array}{l}\text { Linguagem natural no } \\
\text { twitter e linguagem } \\
\text { documentária em } \\
\text { tesauros: da hashtag } \\
\text { \#NãoMereçoSerEstuprad } \\
\text { a ao descritor estupro. }\end{array}$ & $\begin{array}{c}\text { Ciência da } \\
\text { Informação. } \\
\text { Linguagem natural. } \\
\text { Linguagem } \\
\text { documentária. } \\
\text { Twitter. } \\
\text { Representação } \\
\text { Temática da } \\
\end{array}$ & 2016 & $\begin{array}{l}\text { InCID: R. Ci. } \\
\text { Inf. e Doc., } \\
\text { Ribeirão Preto }\end{array}$ \\
\hline
\end{tabular}




\begin{tabular}{|c|c|c|c|c|}
\hline & & $\begin{array}{c}\text { Informação. Estupro. } \\
\text { Tesauro Brased. } \\
\text { Tesauro STJ. }\end{array}$ & & \\
\hline $\begin{array}{l}\text { BOCCATO, } \\
\text { V. R. C.; } \\
\text { TORQUETTI, } \\
\text { M. C. }\end{array}$ & $\begin{array}{l}\text { Interoperabilidade entre } \\
\text { linguagens de indexação } \\
\text { como recurso de } \\
\text { modelagem de repertório } \\
\text { terminológico de } \\
\text { coordenadorias de } \\
\text { comunicação social em } \\
\text { ambientes universitários: } \\
\text { uma proposta } \\
\text { metodológica. }\end{array}$ & $\begin{array}{l}\text { Ciência da } \\
\text { Informação. } \\
\text { Organização e } \\
\text { representação do } \\
\text { conhecimento. } \\
\text { Linguagens de } \\
\text { indexação. } \\
\text { Interoperabilidade. } \\
\text { Metodologia. } \\
\text { Clippings. }\end{array}$ & 2012 & $\begin{array}{c}\text { Informação \& } \\
\text { Informação }\end{array}$ \\
\hline
\end{tabular}

Fonte: Dados da pesquisa.

O estudo de linguagens documentárias é sem dúvida um dos pontos primordiais para a realização da indexação. Essa categoria apresentou ocorrência em três dos artigos recuperados. Nos casos descritos, todos os artigos mostraram as linguagens documentárias como mediadoras para recuperação de informação em ambientes digitais. $\mathrm{O}$ uso dessas linguagens enquanto instrumento de representação e recuperação da informação permite a comunicação entre o documento, a informação e o usuário (JESUS, 2002). É nesse sentido que os estudos foram apresentados, ressaltando as linguagens documentárias como forma de padronização dos conceitos selecionados visando à representação dos assuntos tratados nos documentos.

Quadro 4 - Estudos semânticos

\begin{tabular}{|c|c|c|c|c|}
\hline \multicolumn{5}{|c|}{ Estudos semânticos } \\
\hline Autores & Título do artigo & Palavras-chave & Ano & Periódico \\
\hline $\begin{array}{l}\text { CATARINO, M. } \\
\text { E.; } \\
\text { CERVANTES, } \\
\text { B. G. M. N.; } \\
\text { ALMEIDA, I. A. }\end{array}$ & $\begin{array}{l}\text { A representação } \\
\text { temática no } \\
\text { contexto da web } \\
\text { semântica. }\end{array}$ & $\begin{array}{l}\text { Ciência da Informação. } \\
\text { Web semântica. } \\
\text { Representação temática. } \\
\text { Ontologia. OWL. } \\
\text { SKOS. Ciência da } \\
\text { Informação. }\end{array}$ & 2015 & $\begin{array}{l}\text { Informação \& } \\
\text { Sociedade: } \\
\text { Estudos }\end{array}$ \\
\hline $\begin{array}{l}\text { MELO, M. A. } \\
\text { F.; } \\
\text { BRÄSCHER, M. }\end{array}$ & $\begin{array}{c}\text { Requisitos } \\
\text { funcionais para } \\
\text { dados de } \\
\text { autoridade assunto } \\
\text { (frsad): entidades, } \\
\text { atributos e } \\
\text { relacionamentos. }\end{array}$ & $\begin{array}{c}\text { Representação } \\
\text { Temática da } \\
\text { Informação. Descrição } \\
\text { de assunto. Requisitos } \\
\text { Funcionais para Dados } \\
\text { de Autoridade Assunto } \\
\text { - FRSAD. }\end{array}$ & 2014 & $\begin{array}{l}\text { Revista Digital } \\
\text { de } \\
\text { Biblioteconomia } \\
\text { \& Ciência da } \\
\text { Informação }\end{array}$ \\
\hline $\begin{array}{l}\text { SOUSA, B. P.; } \\
\text { ALMEIDA, C. } \\
\text { C. N. }\end{array}$ & $\begin{array}{l}\text { Um olhar } \\
\text { semiótico sobre o } \\
\text { processo de } \\
\text { indexação: a } \\
\text { questão da } \\
\text { representação e do } \\
\text { referente. }\end{array}$ & $\begin{array}{c}\text { Processo de Indexação. } \\
\text { Representação da } \\
\text { informação. Referente. } \\
\text { Semiótica. Charles } \\
\text { Peirce (1839-1914). }\end{array}$ & 2012 & $\begin{array}{l}\text { Informação \& } \\
\text { Sociedade: } \\
\text { Estudos }\end{array}$ \\
\hline
\end{tabular}

Fonte: Dados da pesquisa. 
Os estudos referentes ao senso das coisas e dos objetos do mundo são a base para a representação temática da informação. O contexto de emprego das palavras nessa atividade requer um entendimento aprofundado de seus aspectos linguísticos de uso no discurso, pois, na percepção de Bentes Pinto (2001, p. 4) no esquema de indexação, "as palavras são retiradas do contexto do lógicosemântico onde elas tinham uma significação determinada por este contexto". Logo, "se elevadas do mundo real, elas designam um conjunto de propriedades, seu sentido muda e se resume a um conjunto de unidades lexicais". Na mesma direção, Michel Le Guern (1991, p. 23) argumenta que “A palavra da língua, contrariamente às suas ocorrências no discurso, não tem referências extralinguísticas. (...)", por isso o cuidado quando da seleção das "pistas" adotadas nos esquemas cognitivos da representação da informação.

A maior dificuldade da indexação é a escolha do assunto que melhor represente os temas abordados nos documentos. Isso requer que o indexador procure seguir as políticas de indexação adotadas pelas organizações com relação ao uso de conceitos, termos, sintagmas, palavras-chave, descritores ou outros.

Os três artigos recuperados apontam pesquisas de aplicação de modelos conceituais para a extração de assuntos.

Quadro 5 - Mapas conceituais e cognitivos

\begin{tabular}{|c|c|c|c|c|}
\hline Autores & Título do artigo & Palavras- chave & Ano & Periódico \\
\hline $\begin{array}{c}\text { RODRIGUES, M. } \\
\text { R.; } \\
\text { CERVANTES, B. } \\
\text { G. M. N. }\end{array}$ & $\begin{array}{c}\text { Análise de assunto e mapas } \\
\text { conceituais: semelhanças } \\
\text { nos processos. }\end{array}$ & $\begin{array}{c}\text { Ciência da Informação. } \\
\text { Biblioteconomia. } \\
\text { Tratamento Temático } \\
\text { da Informação. Análise } \\
\text { de assunto. Mapas } \\
\text { conceituais. }\end{array}$ & 2015 & $\begin{array}{c}\text { Perspectivas } \\
\text { em Ciência da } \\
\text { Informação }\end{array}$ \\
\hline $\begin{array}{c}\text { MELO, A. V. C. } \\
\text { de }\end{array}$ & $\begin{array}{c}\text { Mapas cognitivos e } \\
\text { categorias temáticas como } \\
\text { metodologias associadas de } \\
\text { análise e organização de } \\
\text { dados em pesquisa } \\
\text { qualitativa. }\end{array}$ & $\begin{array}{c}\text { Arquivologia. Pesquisa } \\
\text { qualitativa. } \\
\text { Metodologia. } \\
\text { Categorização. Mapas } \\
\text { cognitivos. }\end{array}$ & 2012 & $\begin{array}{c}\text { Informação e } \\
\text { Sociedade }\end{array}$ \\
\hline MELO, A. V. C. & $\begin{array}{c}\text { Contribuições possíveis dos } \\
\text { estudos sobre processos } \\
\text { cognitivos para a } \\
\text { Representação Temática da } \\
\text { Informação. }\end{array}$ & $\begin{array}{c}\text { Representação da } \\
\text { informação. Cognição. }\end{array}$ & 2013 & $\begin{array}{c}\text { Perspectivas } \\
\text { em Gestão \& } \\
\text { Conheci- } \\
\text { mento }\end{array}$ \\
\hline
\end{tabular}

Fonte: Dados da pesquisa. 
Os mapas conceituais auxiliam no entendimento de conceitos por meio da categorização hierarquizada de um determinado tema ou assunto, estudo que contribui para a representação temática. Tanto os mapas conceituais quanto os cognitivos são representações informacionais, baseadas em esquemas que podem apresentar os conceitos e suas relações. O primeiro artigo (quadro 5) dessa categoria faz um estudo comparativo do processo de elaboração de mapas conceituais e de análise de assuntos. Os autores ressaltam o quanto essas duas atividades se assemelham e apresentam contribuições para a organização e a representação do conhecimento. Os outros dois artigos enfatizam os estudos cognitivos na construção de instrumentos de indexação.

Quadro 6 - Indexação de imagens

\begin{tabular}{|c|c|c|c|c|}
\hline Autores & Título do artigo & Palavras-chave & $\begin{array}{c}\text { An } \\
0\end{array}$ & Periódico \\
\hline $\begin{array}{c}\text { MACHADO, V. F.; } \\
\text { ALBUQUERQUE, } \\
\text { A. C. }\end{array}$ & $\begin{array}{l}\text { A representação temática } \\
\text { da xilogravura: o } \\
\text { processo de indexação } \\
\text { da coleção Paulo } \\
\text { Menten. }\end{array}$ & $\begin{array}{c}\text { Xilogravura. } \\
\text { Representação da } \\
\text { informação. } \\
\text { Indexação. Paulo } \\
\text { Menten. }\end{array}$ & $\begin{array}{c}201 \\
6\end{array}$ & $\begin{array}{l}\text { Revista ACB: } \\
\text { Biblioteco- } \\
\text { nomia em } \\
\text { Santa Catarina }\end{array}$ \\
\hline $\begin{array}{c}\text { SILVA, C. S.; } \\
\text { BERNARDINO, } \\
\text { M. C. R.; } \\
\text { ELLIOTT, A. G. }\end{array}$ & $\begin{array}{l}\text { Processamentos técnicos } \\
\text { nas xilogravuras do } \\
\text { laboratório de Ciência da } \\
\text { Informação e Memória: } \\
\text { relato de experiência. }\end{array}$ & $\begin{array}{l}\text { Catalogação e } \\
\text { indexação. } \\
\text { Xilogravuras. }\end{array}$ & $\begin{array}{c}201 \\
7\end{array}$ & $\begin{array}{c}\text { Revista } \\
\text { Brasileira de } \\
\text { Biblioteco- } \\
\text { nomia e } \\
\text { Documenta- } \\
\text { ção }\end{array}$ \\
\hline
\end{tabular}

Fonte: Dados da pesquisa.

Não foi surpresa, devido a sua popularidade nos estudos em representação temática, que tenhamos recuperado dois artigos tratando da indexação de imagens; no entanto, a sua aplicação às xilogravuras é ímpar e não muito comum. Os dois artigos (quadro 6) são semelhantes e apresentam relatos de experiências no processo de indexação de xilogravuras, arte de transferir a imagem desenhada na madeira para o papel. Segundo Machado e Albuquerque (2016, p. 859), “os recursos imagéticos, no caso de estudo as xilogravuras, contêm informações que precisam ser tratadas, ou seja, elas precisam ser organizadas e representadas [...]", e isso requer princípios adequados que respeitem as características desses documentos. 
Quadro 7 - Bibliotecas universitárias

\begin{tabular}{|c|c|c|c|c|}
\hline Autores & Título do artigo & Palavras-chave & Ano & Periódico \\
\hline $\begin{array}{l}\text { BRAZ, M. R. } \\
\text { I.; } \\
\text { CARVALHO, } \\
\text { E. S. }\end{array}$ & $\begin{array}{l}\text { Práticas em } \\
\text { tratamento temático } \\
\text { da informação: } \\
\text { interfaces de ensino } \\
\text { e aprendizagem. }\end{array}$ & $\begin{array}{l}\text { Tratamento temático. } \\
\text { Ensino de } \\
\text { Biblioteconomia. Ações } \\
\text { de ensino e extensão. }\end{array}$ & 2017 & $\begin{array}{c}\text { Revista } \\
\text { Brasileira de } \\
\text { Biblioteconomia } \\
\text { e Documentação }\end{array}$ \\
\hline $\begin{array}{l}\text { REDIGOLO, } \\
\text { F. M.; SILVA, } \\
\text { M. V. }\end{array}$ & $\begin{array}{l}\text { A representação } \\
\text { temática como } \\
\text { mediadora } \\
\text { implícita da } \\
\text { informação em } \\
\text { bibliotecas } \\
\text { universitárias. }\end{array}$ & $\begin{array}{l}\text { Ciência da Informação. } \\
\text { Biblioteconomia. } \\
\text { Mediação da informação. } \\
\text { Tratamento Temático da } \\
\text { Informação. Bibliotecas } \\
\text { universitárias. }\end{array}$ & 2017 & Ponto de Acesso \\
\hline SOUSA, B. P. & $\begin{array}{c}\text { Representação } \\
\text { Temática da } \\
\text { Informação } \\
\text { documentária e sua } \\
\text { contextualização } \\
\text { em biblioteca. }\end{array}$ & $\begin{array}{c}\text { Tratamento da } \\
\text { informação - biblioteca. } \\
\text { Indexação. Informação } \\
\text { documentária. }\end{array}$ & 2013 & $\begin{array}{c}\text { Revista } \\
\text { Brasileira de } \\
\text { Biblioteconomia } \\
\text { e Documentação }\end{array}$ \\
\hline
\end{tabular}

Fonte: Dados da pesquisa.

A relação dos estudos de indexação envolvendo as bibliotecas em geral parece ser uma prática comum. Destacamos aqui os artigos que apresentam propostas voltadas aos ambientes universitários. Os três documentos relatam o impacto do tratamento temático da informação, com destaque para o papel dessa atividade como mediadora do conhecimento, pois a escolha adequada dos assuntos fará com que o usuário chegue ao documento que procura. Essa preocupação é latente nas bibliotecas universitárias, devido ao grau de exigência e especialização dos usuários, o que requer do indexador uma postura ainda mais atenta na escolha dos assuntos, bem como no controle de qualidade da indexação.

Quadro 8 - Bibliotecas digitais/repositórios digitais

\begin{tabular}{|c|c|c|c|c|}
\hline Autores & Título do artigo & Palavras-chave & Ano & Periódico \\
\hline $\begin{array}{c}\text { SANTOS, } \\
\text { R. F. }\end{array}$ & $\begin{array}{l}\text { Indexação em repositórios } \\
\text { digitais: uma abordagem } \\
\text { sobre o metadado assunto da } \\
\text { Biblioteca Digital de } \\
\text { Monografias da UFRN. }\end{array}$ & $\begin{array}{c}\text { Representação } \\
\text { Temática da } \\
\text { Informação. } \\
\text { Indexação. Metadado } \\
\text { assunto. Repositórios } \\
\text { digitais. }\end{array}$ & 2017 & $\begin{array}{c}\text { Revista } \\
\text { Informação na } \\
\text { Sociedade } \\
\text { Contemporânea }\end{array}$ \\
\hline $\begin{array}{l}\text { SIMÕ̃ES, } \\
\text { K. O.; } \\
\text { MORAES, } \\
\text { M. G. }\end{array}$ & $\begin{array}{l}\text { Proposta de modelagem } \\
\text { conceitual para a } \\
\text { organização da informação } \\
\text { na biblioteca virtual em } \\
\text { saúde, prevenção e controle } \\
\text { de câncer. }\end{array}$ & $\begin{array}{l}\text { Organização da } \\
\text { informação. } \\
\text { Linguagens } \\
\text { documentárias. } \\
\text { Sistemas de } \\
\text { organização do } \\
\text { conhecimento. } \\
\text { Modelagem }\end{array}$ & 2015 & $\begin{array}{c}\text { Revista } \\
\text { Analisando em } \\
\text { Ciência da } \\
\text { Informação }\end{array}$ \\
\hline
\end{tabular}




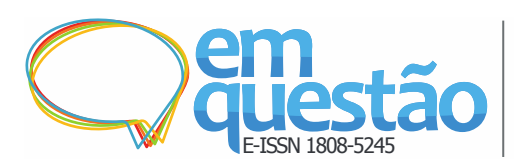

Tendências nos estudos de Representação Temática da Informação: uma revisão integrativa dos artigos

científicos indexados na Brapci

Camila Regina de Oliveira Rabelo e Virgínia Bentes Pinto

\begin{tabular}{|c|c|c|c|c|}
\hline & & conceitual. & & \\
\hline $\begin{array}{l}\text { PAES, D. } \\
\text { M. B.; } \\
\text { TABOSA, } \\
\text { H. R. }\end{array}$ & $\begin{array}{l}\text { Biblioteca Digital de Teses e } \\
\text { Dissertações: reflexões sobre } \\
\text { representação da informação } \\
\text { com vistas à recuperação da } \\
\text { informação. }\end{array}$ & $\begin{array}{l}\text { Biblioteconomia. } \\
\text { Representação } \\
\text { informacional. } \\
\text { Metadados. } \\
\text { Biblioteca digital de } \\
\text { teses e dissertações. } \\
\text { Biblioteca digital. }\end{array}$ & 2015 & $\begin{array}{c}\text { Revista ACB: } \\
\text { Biblioteconomia } \\
\text { em Santa } \\
\text { Catarina }\end{array}$ \\
\hline $\begin{array}{c}\text { PEREIRA, } \\
\text { F. A. }\end{array}$ & $\begin{array}{l}\text { A importância da prática de } \\
\text { indexação para a } \\
\text { recuperação da informação: } \\
\text { relato da BV-FAPESP. }\end{array}$ & $\begin{array}{l}\text { Bibliotecas virtuais. } \\
\text { Indexação. Assuntos. } \\
\text { Tratamento da } \\
\text { informação. } \\
\text { Recuperação da } \\
\text { informação. } \\
\end{array}$ & 2015 & $\begin{array}{c}\text { Revista } \\
\text { Brasileira de } \\
\text { Biblioteconomia } \\
\text { e Documentação }\end{array}$ \\
\hline
\end{tabular}

Fonte: Dados da pesquisa.

Localizamos quatro artigos relacionados à indexação nas bibliotecas digitais e repositórios institucionais, todos preocupados em garantir a recuperação da informação.

Quadro 9 - Indexação de textos de literatura

\begin{tabular}{|c|c|c|c|c|}
\hline Autores & Título do artigo & Palavras-chave & Ano & Periódico \\
\hline $\begin{array}{l}\text { ALVES, R. C. V.; } \\
\text { MORAES, J. O. } \\
\text { B. E. }\end{array}$ & $\begin{array}{l}\text { Aboutness em } \\
\text { análise } \\
\text { documental de } \\
\text { textos literários } \\
\text { infantojuvenis: } \\
\text { perspectivas para } \\
\text { o aprimoramento } \\
\text { da representação } \\
\text { de conteúdo. }\end{array}$ & $\begin{array}{l}\text { Ciência da Informação. } \\
\text { Análise documental. } \\
\text { Resumo. Aboutness. } \\
\text { Texto narrativo } \\
\text { ficcional } \\
\text { infantojuvenil. Teoria } \\
\text { da narrativa. }\end{array}$ & 2016 & $\begin{array}{l}\text { Informação \& } \\
\text { Sociedade: } \\
\text { Estudos }\end{array}$ \\
\hline $\begin{array}{l}\text { MAIA, M. E. N.; } \\
\text { ALBUQUER- } \\
\text { QUE, M. E. B. C. }\end{array}$ & $\begin{array}{l}\text { O uso da análise } \\
\text { da informação nos } \\
\text { processos de } \\
\text { indexação para o } \\
\text { contexto do } \\
\text { cordel. }\end{array}$ & $\begin{array}{l}\text { Tratamento da } \\
\text { informação. Análise da } \\
\text { informação. Cordel. } \\
\text { Indexação. }\end{array}$ & 2014 & $\begin{array}{c}\text { BIBLOS - } \\
\text { Revista do } \\
\text { Instituto de } \\
\text { Ciências } \\
\text { Humanas e da } \\
\text { Informação }\end{array}$ \\
\hline
\end{tabular}

Fonte: Dados da pesquisa.

Em sua aplicação tradicional, a indexação, como parte do processo de catalogação de assuntos de livros, tem o objetivo de identificar os principais assuntos tratados na obra para que os documentos sejam recuperados. Visa ainda que o usuário tenha uma noção da temática abordada e possa julgar se é relevante ou não para atender a sua necessidade informacional. Os dois resultados aqui apresentados encaixam-se bem nessa categoria, tratando dos assuntos para representação de textos infantojuvenis e da literatura de cordel. 
Quadro 10 - Ensino da Representação Temática da Informação na modalidade a distância

\begin{tabular}{|c|c|c|c|c|}
\hline Autor & Título do artigo & Palavras-chave & Ano & Periódico \\
\hline & O ensino de & Ensino de & & \\
& Representação & Biblioteconomia. & & \\
& Temática da & Representação Temática & & Revista ACB: \\
SILVEIRA, & Informação a & da Informação. & \multirow{2}{*}{2015} & $\begin{array}{c}\text { Bibliotecono- } \\
\text { mia em Santa } \\
\text { J. P. B. da }\end{array}$ \\
& distância: a & Classificação & & Catarina \\
& experiência da & bibliográfica. Educação a & & \\
& Universidade de & distância. Universidade & & \\
& Caxias do Sul - UCS. & de Caxias do Sul - UCS. & & \\
\hline
\end{tabular}

Fonte: Dados da pesquisa.

A Representação Temática da Informação é estudada enquanto disciplina obrigatória nos cursos de Biblioteconomia, recebendo, em alguns casos, o nome de Indexação, Tratamento Temático da Informação, Descrição Temática da Informação, entre outros. O artigo apresentado no quadro 10 refere-se a um relato de experiência do ensino da disciplina de Representação Temática da Informação na modalidade de ensino a distância (EaD). A ocorrência de um único artigo abordando essa temática deve-se ao fato de não ser comum a oferta de disciplinas em EaD, por serem os cursos de Biblioteconomia predominantemente presenciais. É possível que estudos futuros apareçam nessa direção, por conta do surgimento da primeira oferta no Brasil do curso de Biblioteconomia em EaD, aprovado em 2018.

Percebemos que há equilíbrio entre os resultados apresentados, com destaque para a quantidade de artigos que abordam a representação temática no ambiente das bibliotecas e dos repositórios digitais.

\section{Considerações finais}

A revisão integrativa, objetivo deste artigo, nos permitiu mapear os principais assuntos que estão sendo estudados no contexto da Representação Temática da Informação e discutir a sua importância enquanto objeto de estudo. Os resultados mostraram que há destaque para os artigos que apresentam relatos de experiência, mesmo sabendo que o incentivo maior para publicações periódicas vem dos acadêmicos, e há também a preocupação dos profissionais que estão no mercado de trabalho em divulgar os resultados de seus estudos. 
Outro ponto que vale ressaltar é a diversidade de documentos com os quais bibliotecários e arquivistas trabalham, fazendo com que a representação temática seja estudada de acordo com as características do campo do conhecimento a que se aplica. Esse fato evidencia a importância de estudos e pesquisas contemplando outras áreas para que a recuperação da informação proporcione resultados mais eficazes na indexação de assuntos.

Nesta pesquisa fica evidente que a aplicabilidade da revisão integrativa para estudos concernentes à representação temática pode trazer grandes contribuições, principalmente para se conhecer o estágio em que se encontram as investigações sobre a evolução da temática em questão.

Para fechar esta conclusão, acreditamos que este artigo pode trazer contribuições para outros trabalhos que envolvam a revisão integrativa, possibilitando a interdisciplinaridade entre as áreas de Biblioteconomia, Ciência da Informação, Computação, Arquivologia, Museologia e outras.

\section{Referências}

BENTES PINTO, Virginia; MEUNIER, Jean-Guy; SILVA NETO, Casemiro. A contribuição peirciana para a representação indexal de imagens visuais.

Encontros Bibli, Florianópolis, n. 25, 2008.

BENTES PINTO, V. Indexação documentária: uma forma de representação do conhecimento registrado. Perspectivas em Ciência da Informação, Belo Horizonte, v. 6, n. 2, p. 223-234, 2001.

BOTTERO, J. Mésopotamie: l'écriture, la raison et les dieux. Paris: Gallimard, 1987.

BOULNOIS, Olivier. Être et représentation. Paris: Presses Universitaires de France, 1999.

CAMPOS, Maria Luiza de Almeida. Perspectivas para o estudo da área de representação da informação. Ciência da Informação, Brasília, v. 25, n. 2, p. 17, 1995.

CARNEIRO, Marilia Vidigal. Diretrizes para uma política de indexação.

Revista da Escola de Biblioteconomia da UFMG, Belo Horizonte, v. 14, n. 2, p. 221-241, set. 1985. 
CHAUMIER, Jacques. Indexação: conceito, etapas e instrumentos. Revista Brasileira de Biblioteconomia e Documentação, São Paulo, v. 21, n. 1/2, p. 63-79, 1988.

FERNEDA, Edberto. Recuperação da informação: análise sobre a contribuição da Ciência da Computação para a Ciência da Informação. 2003. Tese (Doutorado em Ciência da Comunicação) - Universidade de São Paulo, São Paulo, 2003.

FERREIRA, Ana Carolina; MACULAN, Benildes Coura Moreira Santos; ALMEIDA, Josiana Florencio Vieira Regis de. Fundamentos teóricos da representação temática da informação jurídica. CAJUR - Caderno de Informações Jurídicas, [S.l], v. 4, n. 1, 2017.

FRANÇA, Fabiana da Silva. Formas de redução léxica na redação de resumos de alta em prontuário do paciente visando à indexação e recuperação da informação. 2016. Tese (Doutorado em Ciência da Informação) - Universidade Federal da Paraíba, Paraíba, 2016.

FUJITA, Mariângela Spotti Lopes (org.) et al. A indexação de livros: a percepção de catalogadores e usuários de bibliotecas universitárias. Um estudo de observação do contexto sociocognitivo com protocolos verbais [on-line]. São Paulo: Editora Unesp, 2009.

GANONG, Lawrence H. Integrative reviews of nursing research. Research in Nursing and Health, [s. l.], v. 10, n. 1, p. 1-11, 1987.

JESUS, Joracir Botelho Marques de. Tesauro: um instrumento de representação do conhecimento em sistemas de recuperação da informação. In: SEMINÁRIO NACIONAL DE BIBLIOTECAS UNIVERSITÁRIAS, 12., 2002, Recife. Anais [...] Recife: UFPE, 2002.

LANCASTER, Frederick Wilfrid. Indexação e resumos: teoria e prática. 2. ed. Brasília, DF: Briquet de Lemos, 2004.

LE GUERN, M. Un analyseur morpho-syntaxique pour l'indexation automatique. Le français moderne, [s. l.], v. 59, n. 1, p. 22- 35, 1991.

MACHADO, Viviane Faria; ALBUQUERQUE, Ana Cristina de. A representação temática da xilogravura: o processo de indexação da coleção Paulo Menten. Revista ACB: Biblioteconomia em Santa Catarina, Florianópolis, v. 21, n. 3, 2016.

MENDES, Karina Dal Sasso; SILVEIRA, Renata Cristina de Campos Pereira; GALVÃO, Cristina Maria. Revisão integrativa: método de pesquisa para a incorporação de evidências na saúde e na enfermagem. Texto Contexto Enfermagem, Florianópolis, v. 17, n. 4, dez. 2008. 
ROBREDO, J. Documentação de hoje e de amanhã: uma abordagem revisitada e contemporânea da Ciência da Informação e de suas aplicações biblioteconômicas, documentárias, arquivísticas e museológicas. 4. ed. Brasília, 2005.

SILVA, Márcio Bezerra da; SOUSA, Dulce Elizabeth Lima de; BANDEIRA, Pablo Matias. A representação temática em documentos arquivísticos: o caso da indexação documental realizada pelos alunos de Arquivologia da UFPB. InCID: Revista de Ciência da Informação e Documentação, [s. l.], v. 3, n. 2, p. 124-141, 2012.

SILVEIRA, Renata Cristina de Campos Perreira; GALVÃO, Cristina Maria. O cuidado de enfermagem e o cateter Hickman: a busca de evidências. Acta Paulista de Enfermagem, São Paulo, v. 3, n. 18, p. 276-284, 2005.

SOUZA, Marcela Tavares de; SILVA, Michelly Dias da; CARVALHO, Rachel de. Revisão integrativa: o que é e como fazer. Einstein, São Paulo, v. 8, n. 1, p. 102-106, mar. 2010.

TORRACO, Richard J. Writing integrative literature reviews: guidelines and examples. Human Resource Development Review, [s.l.], v. 4, n. 3, p. 356-367, set. 2005.

VIEIRA, Simone Bastos. Indexação automática e manual: revisão de literatura. Ciência da Informação, Brasília, v. 17, n.1, p. 43-57, jan./jun. 1988.

\title{
Trends in Thematic Representation of Information Studies: an integrative review of scientific articles indexed in Brapci
}

\begin{abstract}
This article presents the investigation results of a basic objective to verify, through integrative bibliographic review, trends of subjects related to studies and researches contemplating thematic representation in scientific articles indexed in Base de Dados Referenciais de Artigos de Periódicos em Ciência da Informação. We understand thematic representation or indexation as a complex scheme of actions that aim to identify the main subjects of a document in order to offer "clues" for information retrieval. This research is based on Revisão Bibliográfica Integrativa, a methodology that allows synthesizing content found in scientific literature to evidence manifestation of a certain subject and assisting in subsequent research. The locus of this empirical study was the Base de Dados Referenciais de Artigos de Periódicos em Ciência da Informação database, within the period of 2012-2017. The results show a total of twenty-five articles concerning thematic representation of information, with research tendencies including: Archivology, indexing of legal documents, documentary languages, semantic studies, conceptual maps, indexing of images,
\end{abstract}


university libraries, digital libraries/digital repositories, indexing of literature texts, teaching of thematic representation at a distance. It is concluded that trends of studies and research on thematic representation of information contemplate applications diversity with greater function of access and retrieval of documents.

Key-words: Integrative review. Thematic Representation of Information. Indexing of subjects. Representation of information. Research in Information Science.

Recebido: 26/04/2018

Aceito: 08/10/2018 